\title{
Motor impairment in a rare form of spastic paraplegia (Spoan syndrome): a 10-year follow-up
}

\author{
Cláudia R. C. Galvão ${ }^{1 \dagger}$, Priscilla M. A. Cavalcante ${ }^{2 \dagger}$, Ricardo Olinda ${ }^{3}$, Zodja Graciani ${ }^{4}$, Mayana Zatz ${ }^{5}$, Fernando Kok ${ }^{6}$, \\ Silvana Santos ${ }^{7 *+}$ and Selma Lancman ${ }^{2+}$
}

\begin{abstract}
Background: Spastic paraplegia, optic atrophy and neuropathy (Spoan syndrome) is an autosomal recessive disease with approximately 70 cases recorded in Brazil and Egypt.

Methods: This is a prospective longitudinal study performed with 47 patients affected with Spoan syndrome of seven communities of Rio Grande do Norte (Brazil) to investigate changes in motor function based on comparative data obtained from a 10-year follow-up.

Results: The mean age of the participants was $47.21 \pm 12.42$ years old, and the mean age at loss of ambulation and hand function were $10.78 \pm 5.55$ and $33.58 \pm 17.47$ years old, respectively. Spearman's correlation analysis between the score on the Modified Barthel Index and the investigated variables evidenced statistical significance for age $(p<0.001)$ and right- and left-hand grip strength $(p=0.042$ and $p=0.021$, respectively). Statistical significance was not evidenced for the remainder of the variables, including age at onset of symptoms $(p=0.634)$, age at loss of ambulation $(p=0.664)$ and age at loss of hand function $(p=0.118)$.

Conclusions: Our analysis allows asserting that the participants exhibited slight dependence until age 35 . The greatest losses occurred from ages 35 to 41, and starting at 50, practically all patients become completely dependent. These findings are relevant for determining the prognosis as well as suitable treatment, rehabilitation and assistive technology for these individuals.
\end{abstract}

Keywords: Spastic paraplegia, Optic atrophy, Rare diseases, Longitudinal survey

\section{Background}

Spastic paraplegia, optic atrophy and neuropathy (Spoan syndrome) (OMIM \#609641) is an autosomal recessive disease. Individuals with Spoan syndrome exhibit earlyonset progressive spastic paraplegia, resulting in loss of independent ambulation before adolescence, combined with non-progressive congenital optic atrophy. Axonal neuropathy develops over the first decade of life and results in progressive loss of upper limb function, together with other manifestations, such as dysarthria, shortening of muscles and spine deformities [1,2]. More than 70

\footnotetext{
* Correspondence: silvanasantosuepb@gmail.com; silvanaipe@gmail.com ${ }^{\dagger}$ Cláudia R. C. Galvão, Priscilla M. A. Cavalcante, Silvana Santos and Selma Lancman contributed equally to this work.

${ }^{7}$ Community Genetics Group, State University of Paraíba, Rua das Baraúnas 351, Campina Grande, Paraíba, Brazil

Full list of author information is available at the end of the article
}

cases have been recorded, two in Egypt and all others in Brazil, three in the South and Southeast regions and the remainder mainly in the Northeast [3].

The mutation involved consists of a 216-bp microdeletion in the 11q13 chromosome region, which upregulates the expression of the $K L C 2$ gene product, a kinesin related to axonal transport [3]. The initial diagnosis of Spoan syndrome is made in the clinic, based on neurological examination, followed by genetic testing aiming at detecting the aforementioned mutation, which is performed at the Centre of Studies of the Human Genome, University of São Paulo.

In the area known as Alto Oeste Potiguar, Rio Grande do Norte, Brazil, the prevalence of Spoan syndrome is 1 : 250 inhabitants, and it is estimated that 1 in 15 inhabitants are heterozygous carriers of the mutation [4]. 
Spoan syndrome is thus a genetic disease that causes severe physical disability and has high prevalence in the Brazilian Northeast region. However, the incidence of the disease may be underestimated globally given that some cases might not be diagnosed, as Spoan can be confounded with other simple or complex forms of spastic paraplegia [5].

The aim of this prospective longitudinal study was to investigate a rare form of spastic paraplegia (Spoan syndrome) and changes in motor function based on comparative data obtained from a 10-year follow-up of 47 patients. This data are relevant for the purpose of communicating prognosis to patients and for selecting adequate outcome measures for future clinical studies.

\section{Methods}

The present was a prospective and longitudinal study on the motor function of individuals with confirmed diagnosis of Spoan syndrome in which data collected in 2007 and 2017 were compared. Of the 61 participants in the first assessment, 47 resided in municipalities in Alto Oeste Potiguar, Rio Grande do Norte, and could be located with the help of community health workers. These patients were assessed at home by occupational therapists.

The distribution of the patients per municipality was as follows: São Miguel $(n=17)$, Serrinha dos Pintos $(n=13)$, Pau dos Ferros $(n=5)$, Encanto $(n=4)$, Coronel João Pessoa $(n=3)$, Dr. Severiano $(n=3)$ and Martins $(n=2)$. Fourteen of the participants in the original study were excluded for the following reasons: not residing in the investigated municipalities $(n=6)$, death $(n=8)$ and lack of confirmation of Spoan syndrome on genetic testing $(n=1)$.

The 47 participants in the present study were assessed using the same protocols as the ones used by Graciani and colleagues (2010). The participants were first interviewed to collect data such as date of birth, educational level, age at onset of symptoms and ages at loss of ambulation and hand function. Next, we applied the following instruments for the measurement of motor function parameters:

1. Modified Barthel Index (MBI), described by Shah et al. (1989) [6]: this index determines the degree of dependence of individuals relative to 10 functional categories - (1) personal hygiene, (2) bathing, (3), feeding, (4) toilet use, (5) stair climbing, (6) dressing, (7) bladder control, (8) bowel control, (9) ambulation and (10) transfers. The total score ranges from 0 to 100 , and the results are categorised as follows: $0-20$ - total dependence; 21-60 - severe dependence; 61-90 - moderate dependence; 91-99 - slight dependence; and 100 - independence.
2. Spastic Paraplegia Rating Scale (SPRS) [7]: this instrument consists of 13 variables to measure the severity of spastic paraplegia. The individual scores of variables range from 0 , normal, to 4 , severe impairment. The maximum total score is 52 .

3. Functional Hereditary Spastic Paraplegia Rating Scale (FHSPRS) [8]: this scale measures levels of dysfunction based on functional locomotion impairment and ambulation quality, need of auxiliary devices and percentage of time spent in a wheelchair. It is an ordinal measure that includes descriptions of scores: 0 - absence of functional or ambulation impairment; 5 - maximum impairment, more than $50 \%$ of time spent in a wheelchair.

4. Modified Ashworth Scale (MAS) [9]: a qualitative instrument with ordinal measurements represented by descriptions of scores. Assessment is based on the passive motion of the upper limbs, with the individuals remaining at rest. The spasticity-induced resistance of the quadriceps femoris, triceps surae and hip adductors in the supine position is scored from 0 to 5 .

5. Motor Assessment Scale [10]: this scale allows assessing the ability to remain sitting; a higher score indicates a greater ability.

6. Ambulation Index (DeLuca): described by Hauser (1983) and revised by Chiaravalloti and DeLuca [11]. This index allows characterising and standardising the stage of disease regarding ambulation and need for a wheelchair. A higher score indicates a poorer ability to ambulate.

\section{Statistical tests}

Descriptive measures are expressed as the means and standard deviations when appropriate, and as medians and interquartile ranges otherwise. Data normality was assessed using the Anderson-Darling test. The paired samples t-test was used to compare between time points when distribution was normal; otherwise, the Wilcoxon signed-rank test was used. Groups (2007 and 2017) within the cohort were compared by means of the independent samples $t$-test or the Mann-Whitney $U$ test when the data distribution was non-normal. Categorical variables were analysed using Fisher's test. Correlations were investigated with Pearson's or Spearman's tests.

\section{Results}

The sample consisted of 47 individuals, including $31 \mathrm{fe}$ males and 16 males. A total of 25 participants were illiterate, 14 had attended approximately 4 years of formal schooling, and four had attended 8 years. Only one participant had completed higher education, and three did not answer this question. Twenty-nine participants received the state-provided Continued Assistance Benefit 
corresponding to the equivalent of the minimum wage. The remainder of the sample had no source of income but were instead dependent on relatives. All the data are described based on the comparison of the data collected from the same individuals in 2007 and 2017.

The mean age of the sample was $36.87 \pm 12.50$ in 2007 and 47.21 \pm 12.42 years old in 2017. There was no significant difference $(p>0.05)$ in the mean age between females and males. On the last assessment, the age of the participants varied from 22 to 81 years old. The median age at onset of symptoms was 1 year old, with variations for the first and third quartiles being 1 and 2 years, respectively. The mean age at loss of ambulation was $10.78 \pm 5.5$ years old. Only eight of the participants had preserved hand grip strength as assessed with the Jamar ${ }^{\circ}$ dynamometer (Table 1). Only two participants were still able to walk with some aid.

The Anderson-Darling normality test evidenced that the following variables had non-normal distribution: age in 2007 and 2017; age at loss of hand function; MBI; and SPRS. For this reason, the median values obtained in 2007 and 2017 were compared by means of the MannWhitney U test.

The median score on the MBI differed significantly $(p<0.001)$, indicating that the level of dependence increased over time. The $\mathrm{U}$ test did not detect significant differences in the median scores on SPRS and FHSPRS from 2007 to 2017 (Table 1). These scales were used to assess ambulation ability and the influence of spasticity on ambulation. In $2007,68.08 \%$ of the patients with
Spoan syndrome were already confined to a wheelchair; 10 years later, almost all of them (97.87\%) were wheelchair-bound.

The Motor Assessment Scale results showed that in 2017, $82.97 \%$ of the participants could sit only with support. The results for the Modified Ashworth Scale for that year showed that $34.04 \%$ of the sample exhibited grade 1 and $14.89 \%$ grade 4 spasticity. The unpaired ttest was used to compare means between subgroups (Table 1). The differences between medians were significant for both right- and left-hand grip strength. The median value decreased from 3.33 to $0 \mathrm{kgf}$ on the right hand and from 1.66 to $0 \mathrm{kgf}$ on the left from 2007 to 2017 (Table 1).

At the time of the first assessment in 2007, 14 participants had already fully lost their hand grip strength. Ten years later, this finding was detected in an additional 25 patients, and only eight still exhibited some degree of hand grip strength, as assessed with the Jamar $^{\circledR}$ hydraulic dynamometer; the right hand was the dominant one for all of these cases. Figure 1 depicts the correlations between right- and left-hand grip strength in 2007 and 2017.

Relative to loss of hand function in association with dependence for feeding, among the 26 participants who fully lost their hand function, 15 were total dependent for feeding, while 11 were still able to handle eating utensils, albeit with constant assistance; the scores on the MBI domain feeding ranged from 0 to 2 . Relative to the other 21 participants, the scores on the MBI domain

Table 1 Participants' characteristics and mean and median ages; comparison of values along the analysed 10-year period by means of the Mann-Whitney $U$ test

\begin{tabular}{llll}
\hline Variables & First visit 2007 & Second visit 2017 & $p$-value \\
\hline Number of patients & 47 & 47 & - \\
$\quad$ Male & 16 & 16 & 31 \\
$\quad$ Female & 31 & $47.21 \pm 12.42$ & - \\
Age (years) & $36.87 \pm 12.50$ & $46.81 \pm 9.89$ & - \\
$\quad$ Male & $36.67 \pm 9.90$ & $47.45 \pm 13.70$ & - \\
$\quad$ Female & $36.96 \pm 13.81$ & $1[1.00 ; 2.00]$ & - \\
Age at onset (years) & $1[1.00 ; 2.00]$ & $10.00[7.00 ; 15.00]$ & - \\
Age of gait loss & $10.00[7.00 ; 15.00]$ & $38.00[20.00 ; 41.50]$ & - \\
Age of manual function loss & - & $22.00[18.00 ; 33.50]$ & $<0.001^{\text {a }}$ \\
Barthel Índice & $39.00[24.50 ; 51.50]$ & $0.00[0.00 ; 0.00]$ & $<0.001^{\text {a }}$ \\
Grip strength $R$ & $3.00[0.00 ; 9.00]$ & $0.00[0.00 ; 0.00]$ & $<0.001^{\text {a }}$ \\
Grip strength L & $2.00[0.00 ; 7.00]$ & $41.00[38.00 ; 44.00]$ & 0.195 \\
SPRS & $40.50[38.00 ; 43.75]$ & $9.00[9.00 ; 9.00]$ & 0.982 \\
Deluca & $9.00[8.00 ; 9.00]$ & $1.00[1.00 ; 1.00]$ & 0.257 \\
Smith & $1.00[1.00 ; 2.00]$ & $5.00[5.0 ; 5.0]$ & 0.998 \\
Fink Scale & $5.00[4.0 ; 5.0]$ & &
\end{tabular}

Numbers in brackets represent the interquartile range

${ }^{a}$ Mann-Whitney $U$ test, $p$-value were calculated between first and second visit 

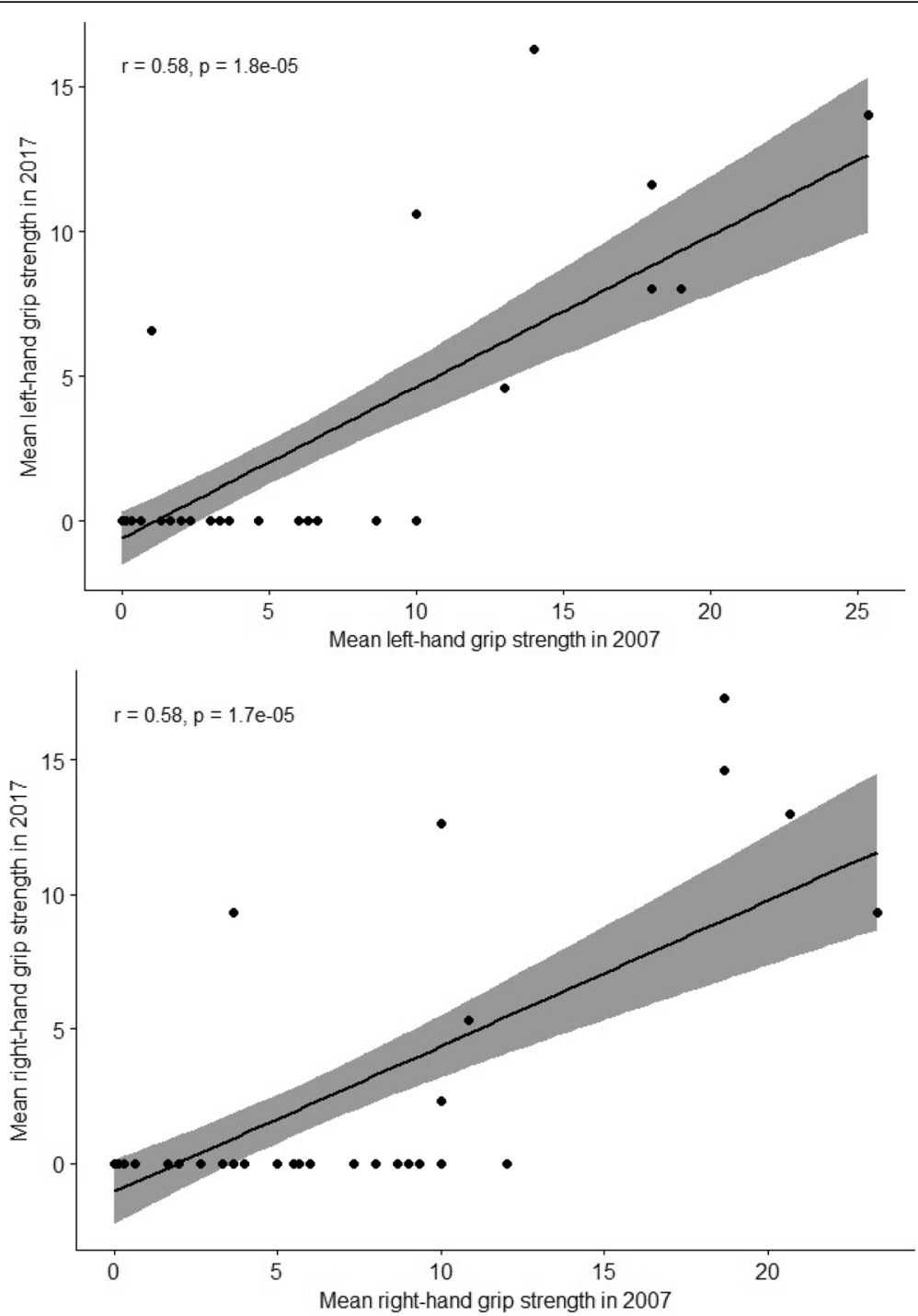

Fig. 1 Correlations between the mean right- and left-hand grip strength in 2007 and 2017

feeding ranged from 5 to 8 ; six were able to eat with supervision, while 15 were able to eat independently.

Non-parametric correlation analysis (Spearman's correlation) between the score on the MBI and the investigated variables evidenced statistical significance for age $(p<0.001)$ and right- and left-hand grip strength $(p=$ 0.042 and $p=0.021$, respectively). Statistical significance was not evidenced for the remainder of the variables, including age at onset of symptoms $(p=0.634)$, SPRS $(p=$ $0.832)$, age at loss of ambulation $(p=0.664)$ and age at loss of hand function $(p=0.118)$.

Since we found correlation between variation in age and $\mathrm{MBI}$, we fit a simple linear regression model to investigate the effect of the level of loss of independence over time. The equation that represents the relationship between these two variables is $\mathrm{y}=52.37-$ $0.30 \mathrm{x}$, where $\mathrm{y}$ is variation in age, and $\mathrm{x}$ the MBI.
The $p$-value for coefficients $\beta_{0}$ and $\beta_{1}$ was $<0.05$, i.e., statistically significant. Figure 2 depicts the regression line fitted to the data.

In $2017,87.23 \%$ of the participants exhibited severe or total dependence according to the score on the MBI. Since the level of dependence increased with age, we performed an analysis of profile plots for a closer look into age ranges, as shown in Fig. 3. More than half of the participants $(58.33 \%)$ within the age range of 31 to 40 years old ( $25.53 \%$ of the sample) were able to perform transfers and self-care activities, albeit with some degree of dependence. In the group aged 41 to 50 years old, $23.40 \%$ exhibited total dependence. However, half of them were still able to eat by themselves with spoons and under continued supervision; some had only their bladder and bowel control preserved and one case exhibited major losses in bathing, dressing and transfer ability 


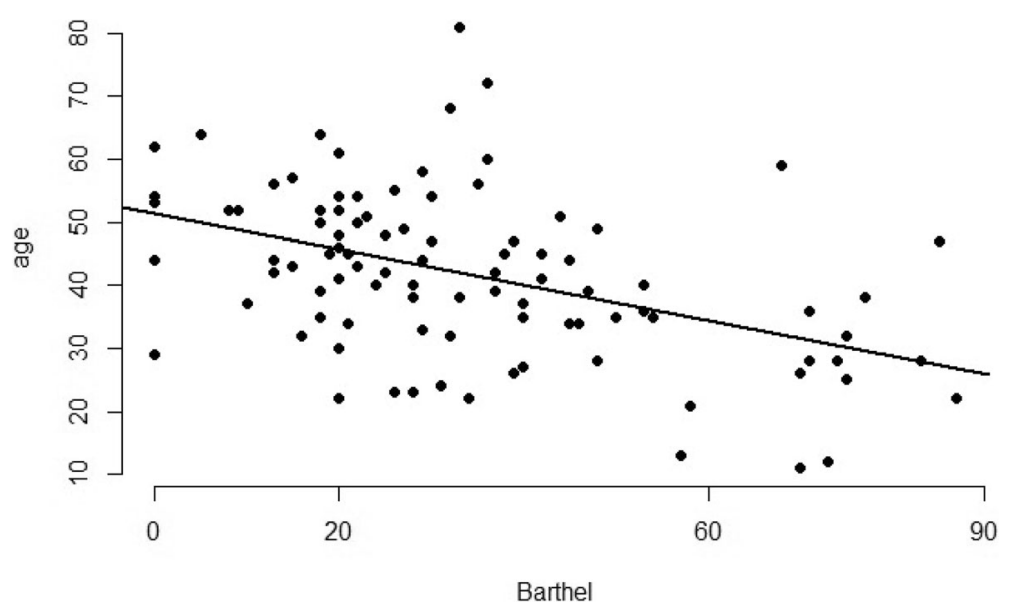

Fig. 2 Linear regression evidencing the relationship between age and MBI(00-20: Total Dependence; 21-60: Severe Dependence; 61-90: Moderate Dependence; 91-99: Slight Dependence; 100: Independence) [6]

(Fig. 3). Most of the participants over 50 years old (44.68\%) exhibited total dependence. Only three patients were still able to participate at some level in their feeding.

\section{Discussion}

The present study is the first longitudinal study of a complex and recessive form of spastic paraplegia prevalent in the semi-arid Northeast region of Brazil. Longitudinal studies are indicated to describe the progression rates in HSP and determine whether the nonlinear increase in disease severity in later disease stages reflects true disease evolution in HSP or represents an artefact of the cross-sectional study design [12]. To our knowledge, only two studies evaluated cross-sectional and longitudinal disease progression in HSP and most of the participants had the dominant forms $[12,13]$.
Our analysis allows asserting that Spoan individuals exhibited slight dependence until age 35 . The greatest losses occurred from ages 35 to 41, and starting at 50, practically all patients become completely dependent. In fact, age is the main predictor factor of impaired motor function among Spoan syndrome patients. Among the 47 reassessed individuals, 14 had already lost their hand grip strength on the first assessment in 2007. Of the remaining individuals, 25 completely lost their hand grip strength over the following 10 years, and eight exhibited partial loss. All the participants needed to use a wheelchair, and only two were able to walk with some aid.

The loss of hand grip strength over the 10-year period was associated with higher levels of dependence. For the eight participants with preserved hand grip strength, the values obtained with the Jamar dynamometer were less than half of the expected values. Unexpectedly, 21 of the participants with no hand grip

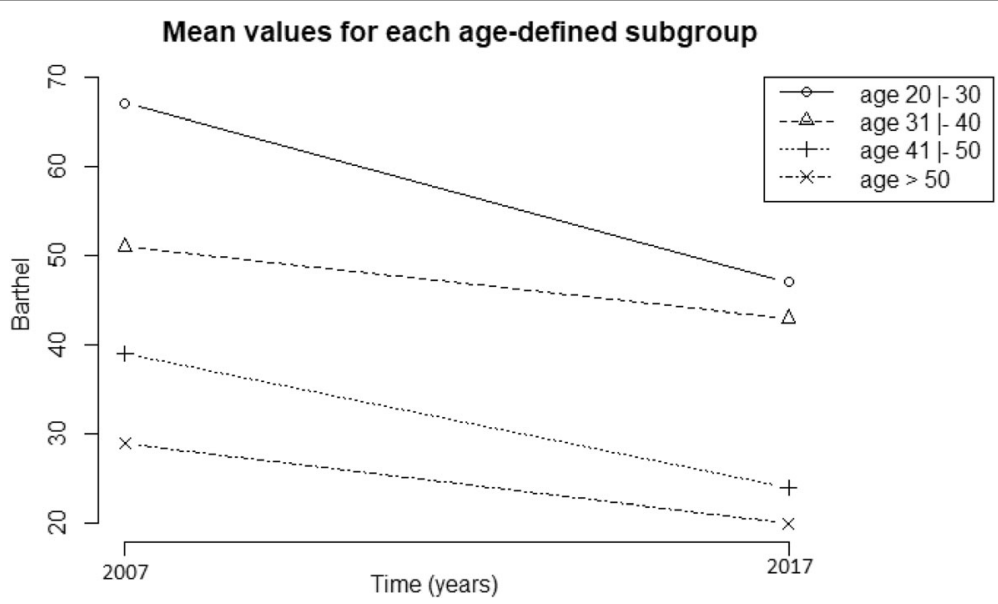

Fig. 3 Profile plot showing the progression of the median scores on the Modified Barthel Index comparatively assessed from 2007 to 2017 , subdivided by age range 
strength were able to feed themselves somehow without any adaptation of the utensils.

The decline in the scores on the functional classification scale reflects the progressive nature of the disease with a marked axonal and sensory-motor neuropathy. Amorim et al. (2014) [14] conducted a study on nerve, motor and sensory conduction that involved 27 cases of people with Spoan syndrome aged between 4 and 58 years, of which 20 were women. All cases had severe neuropathic signs and demonstrated a deficit of force and distal atrophy, and $58 \%$ of them had deformities in the feet and spine. The deep reflexes of the upper limbs were exalted in $92 \%$ of the cases, and the patellar reflex in 63\%; being the Aquileu reflex absent in all patients. No correlation was observed between age and conduction velocity, latency and amplitude of median and ulnar nerves. There was a reduction in conduction velocities in the median and ulnar nerves by 50 and $41 \%$, respectively. The motor latencies of the axillary and femoral nerves were normal in all cases. Changes in driving speed are probably due to the loss of rapidly conducting nerve fibers 20 [14].

Schüle and collaborators (2016) [12] evaluated 608 cases of HSPs and pointed out that the age of onset and disease duration showed the strongest effect on disease severity, whereby late age of onset and longer disease duration were associated with higher SPRS scores. In our cohort, the first symptoms, such as optic atrophy and spastic paraparesis, appear before age five and most frequently during the first year of life. In fact, it was not found a significant variation in the age at onset in Spoan syndrome. For this reason, no correlation was found between age at onset of symptoms and motor impairment or between motor impairment and sex, as described in follow-up studies of other rare genetic diseases $[12,13,15,16]$.

Data from larger cohorts using measures validated for HSP are essentially missing in the literature [15]. In the present study, no significant difference was found on Schüle's SPRS, Fink's FHSPRS or the Ambulation Index revised by Chiaravalloti and DeLuca between 2007 and 2017. The participants' ambulation was already highly impaired at the first assessment in 2007 , as $70.21 \%$ of the sample spent more than $50 \%$ of their time in a wheelchair, and only three were able to walk. In 2017, 45 individuals (97.87\%) had completely lost their ambulation ability and spent their entire days in a wheelchair. A high proportion of affected individuals had minimum or maximum scores on the scales, which might reduce variability of data and explain the outcomes.

Although the patients' life expectancy was not investigated using suitable methods, it does not seem to decrease, since six participants were 60 years old or older, and one was 81 years old. Regarding causes of death, no repeated respiratory problems (pneumonia) were detected, as in other studies on rare genetic diseases $[16,17]$. Therefore, Spoan syndrome is different from conditions such as Duchenne muscular dystrophy, in which the life expectancy is limited to two or three decades as a function of cardiac and respiratory involvement [18], and amyotrophic lateral sclerosis, with a life expectancy of 2 to 5 years after diagnosis $[19,20]$. Some patients exhibited dysphagia, none required a feeding tube. The causes of death bore no relationship to the disease, and included cancer, infarction, stroke and congenital heart disease.

One of the limitations of the present study concerns the number and variety of the instruments applied at the time Spoan syndrome was first described, which restricted the number of predictive variables. For instance, psychological aspects of patients and their quality of life were not investigated on the earlier assessment. Moreover, it was not possible to establish whether rehabilitation and assistive technology might influence the speed of motor function impairment and the development of deformities, because seven individuals were only attending physiotherapy once a week. Residents of the state of Rio Grande do Norte still lack access to specialised rehabilitation services.

\section{Conclusions}

For the first time, age was described as a predictor factor of the clinical outcome in Spoan syndrome. These findings might be relevant for determining the prognosis as well as the suitable treatment, rehabilitation and assistive technology for these individuals.

\section{Abbreviations}

FHSPRS: Functional Hereditary Spastic Paraplegia Rating Scale; kgf: Kilogram-force; KLC2: Kinesin light chain 2 gene; MAS: Modified Ashworth Scale; MBI: Modified Barthel Index; p-value: Probability value; Spoan syndrome: Spastic Paraplegia Optic Atrophy and Neuropathy; SPRS: Spastic Paraplegia Rating Scale

\section{Acknowledgements}

The authors are very grateful to all families, participants and health community workers, the Health Secretary of the state of Rio Grande do Norte and the Health authorities of Serrinha dos Pintos, São Miguel, Coronel João Pessoa, Dr. Severiano, Encanto, Martins and Pau dos Ferros communities.

\section{Authors' contributions}

CRCG, PMAC, SS: study conception, study design, acquisition of data, analysis of data, and drafting the manuscript. RO: statistical analysis FK, ZG, MZ and SL: study design, interpretation of data and review of the manuscript. All authors read and approved the final manuscript.

\section{Funding}

The current study was funded by Universidade Estadual da Paraíba (PROPESQ) and Fundação de Apoio à Pesquisa do Estado da Paraíba (FAPESQ/CNPq - PPSUS 015/2014) and CAPES (PGPTA/Edital 59/2014). The role of the funding body: the design of the study; collection, analysis, and interpretation of data; and in writing the manuscript. 


\section{Availability of data and materials}

The datasets used and/or analysed during the current study are available from the corresponding author on reasonable request.

\section{Ethics approval and consent to participate}

The present study was approved by the Ethics Committee of the University of São Paulo (CAEE 55137316.4.0000.0065). All participants or their guardians received verbal and written explanations regarding the study procedures, and when they agreed, they signed the informed consent form and institutional declaration of approval in accordance with the principles of Resolution 466/12 of the Brazilian National Health Council. The results will be presented to the participants after publication of the study.

\section{Consent for publication}

Not applicable. No personal information is provided in your manuscript.

\section{Competing interests}

The authors declare that they have no competing interests.

\section{Author details}

'Department of Occupational Therapy, Federal University of Paraíba, João Pessoa, Brazil. ${ }^{2}$ Rehabilitation Sciences Program, University of São Paulo, São Paulo, Brazil. ${ }^{3}$ Department of Statistics, State University of Paraiba, Campina Grande, Brazil. ${ }^{4}$ Department of Physical Therapy, Mackenzie Presbyterian University, São Paulo, Brazil. ${ }^{5}$ Department of Genetics and Evolutionary Biology, University of São Paulo, São Paulo, Brazil. 'Department of Neurology, University of São Paulo, São Paulo, Brazil. ${ }^{7}$ Community Genetics Group, State University of Paraíba, Rua das Baraúnas 351, Campina Grande, Paraíba, Brazil.

Received: 20 April 2019 Accepted: 13 September 2019

Published online: 27 October 2019

\section{References}

1. Macedo-Souza LI, Kok F, Santos S, Amorim SC, Starling A, Nishimura A, et al. Spastic paraplegia, optic atrophy, and neuropathy is linked to chromosome 11q13. Ann Neurol. 2005;57:730-7.

2. Macedo-Souza LI, Kok F, Santos S, Licinio L, Lezirovitz K, Cavaçana N, et al. Spastic paraplegia, optic atrophy, and neuropathy: new observations, locus refinement, and exclusion of candidate genes. Ann Hum Genet. 2009;73(3): $382-7$.

3. Melo US, Macedo-Souza LI, Figueiredo T, Muotri AR, Gleeson JG, Coux G, et al. Overexpression ofKLC2due to a homozygous deletion in the non-coding region causes SPOAN syndrome. Hum Mol Genet. 2015;24(24):6877-85.

4. Santos S, Kok F. Weller M, de Paiva FRL, Otto PA. Inbreeding levels in Northeast Brazil: strategies for the prospecting of new genetic disorders. Genet Mol Biol. 2010:33:220-3.

5. Lo Giudice T, Lombardi F, Santorelli FM, Kawarai T, Orlacchio A. Hereditary spastic paraplegia: clinical-genetic characteristics and evolving molecular mechanisms. Exp Neurol. 2014;261:518-39.

6. Shah S, Vanclay F, Cooper B. Improving the sensitivity of the Barthel Index for stroke rehabilitation. J Clin Epidemiol. 1989:42:703-9.

7. Schüle R, Holland-Letz T, Klimpe S, Kassubek J, Klopstock T, Mall V, et al. The Spastic Paraplegia Rating Scale (SPRS): a reliable and valid measure of disease severity. Neurology. 2006;67:430-4.

8. Fink J. Advances in the hereditary spastic paraplegias. Exp Neurol. 2003;184:106-10.

9. Bohannon RW. Smith MB. Interrater reliability of a modified Ashworth scale of muscle spasticity. Phys Ther. 1987;67:206-7.

10. Carr JH, Shepherd RB, Nordholm L, Lynne D. Investigation of a new motor assessment scale for stroke patients. Phys Ther. 1985;65:175-80.

11. Chiaravalloti ND, DeLuca J. Assessing the behavioral consequences of multiple sclerosis: an application of the Frontal Systems Behavior Scale (FrSBe). Cogn Behav Neurol. 2003;16:54-67.

12. Schüle R, Wiethoff S, Martus P, Karle KN, Otto S, Klebe S, et al. Hereditary spastic paraplegia: Clinicogenetic lessons from 608 patients. Ann Neurol. 2016;79:646-58

13. Tezenas du Montcel S, Charles P, Goizet C, Marelli C, Ribai P, Vincitorio C, et al. Factors influencing disease progression in autosomal dominant cerebellar ataxia and spastic paraplegia. Arch Neurol. 2012;69:500-8.
14. Amorim S, Heise CO, Santos S, Macedo-Souza LI, Zatz M, Kok F. Nerve conduction studies in spastic paraplegia, optic atrophy, and neuropathy (SPOAN) syndrome. Muscle Nerve. 2014;49:131-3.

15. Verhamme C, van Schaik IN, Koelman JHTM, de Haan RJ, de Visser M. The natural history of Charcot-Marie-Tooth type 1A in adults: a 5-year follow-up study. Brain. 2009;132(12):3252-62.

16. Cox FM, Titulaer MJ, Sont JK, Wintzen AR, Verschuuren JJGM, Badrising UA. A 12-year follow-up in sporadic inclusion body myositis: an end stage with major disabilities. Brain. 2011;134(11):3167-75.

17. Oh TH, Brumfield KA, Hoskin TL, Kasperbauer JL, Basford JR. Dysphagia in Inclusion Body Myositis. Am J Phys Med Rehabil. 2008:87:883-9.

18. Bushby K, Finkel R, Birnkrant DJ, Case LE, Clemens PR, Cripe L, et al. Diagnosis and management of Duchenne muscular dystrophy, part 2: implementation of multidisciplinary care. Lancet Neurol. 2010;9:177-89.

19. Peng A, Koffman BM, Malley JD, Dalakas MC. Disease progression in sporadic inclusion body myositis: observations in 78 patients. Neurology. 2000:55:296-8.

20. Rinaldi F, Motti D, Ferraiuolo L, Kaspar BK. High content analysis in amyotrophic lateral sclerosis. Mol Cell Neurosci. 2017;80:180-91.

\section{Publisher's Note}

Springer Nature remains neutral with regard to jurisdictional claims in published maps and institutional affiliations.
Ready to submit your research? Choose BMC and benefit from:

- fast, convenient online submission

- thorough peer review by experienced researchers in your field

- rapid publication on acceptance

- support for research data, including large and complex data types

- gold Open Access which fosters wider collaboration and increased citations

- maximum visibility for your research: over $100 \mathrm{M}$ website views per year

At BMC, research is always in progress.

Learn more biomedcentral.com/submissions 